\title{
Visualizing Biomass Cell Wall Degrading Enzyme Complexes and Aggregates
}

Thomas Haas*, Bryon Donohoe*, Yannick Bomble*, Shi-You Ding*, Martin Keller** and Micheal Himmel*

* Biosciences Center, National Renewable Energy Laboratory, 1617 Cole Boulevard, Golden, CO 80401-3305

** Biological and Environmental Sciences, Oak Ridge National Laboratory, PO Box MS6253, Oak Ridge, TN, 37831-6253

A number of anaerobic, biomass-degrading bacteria produce structured enzyme complexes that they display on their cell surface. These complexes, called cellulosomes, are large macromolecular complexes known to contain a variety of biomass-degrading enzymes docked to structural proteins termed scaffoldins that typically contain carbohydrate binding modules (CBM) [1]. Cellulosomes and their structural and enzymatic components may play an important role in bioenergy production and future bio- and nanotechnologies. Several cellulolytic members of the bacterial genus Clostridium produce cellulosomes. To better understand the macromolecular structure and organization of cellulosomes and the biomass-degrading properties of these organisms, we have employed electron tomography of high-pressure frozen/freeze substituted C. cellulolyticum cultures grown on native switchgrass to examine the 3D ultrastructure of the whole, intact cell wall degrading systems [2]. We have also used immunolabeling and transmission electron microscopy (TEM) to detect two major cellulosome components in situ: A processive endocellulase, Cel48F, and a scaffoldin, CipC. Electron tomography has revealed structural details of polycellulosomes and the tethers that anchor polycellulosomes to bacterial cell surfaces. Immuno-EM has verified that the surface structures observed in the tomograms are indeed cellulosomal complexes. Our observations have revealed two distinct cellulosome/cell surface morphologies present in bacterial colonies and that the cellulosome structure allows Clostridium cellulolyticum to employ cell wall deconstruction mechanisms that differ from the mode of action of the free-enzyme systems more typical of biomass degrading fungi [3].

References

[1] E. A. Bayer, R. Lamed. (1986). Journal of Bacteriology. 167(3): 828-836.

[2] D.N Mastronarde (1997). Journal of Structural Biology. 120(3): 343-352

[3] B. S. Donohoe et. al. (2008) Biotechnology and Bioengineering. 103(3): 480-489

[4] Thanks to Stéphanie Perret (Centre National de la Recherche Scientifique, Marseille, France) for the antibodies against C. cellulolyticum Cel48F and CipC-CMB3 used in this study.

[5] This research was supported by the BESC, a U.S. DOE Bioenergy Research Center supported by the OBER in the DOE Office of Science. 


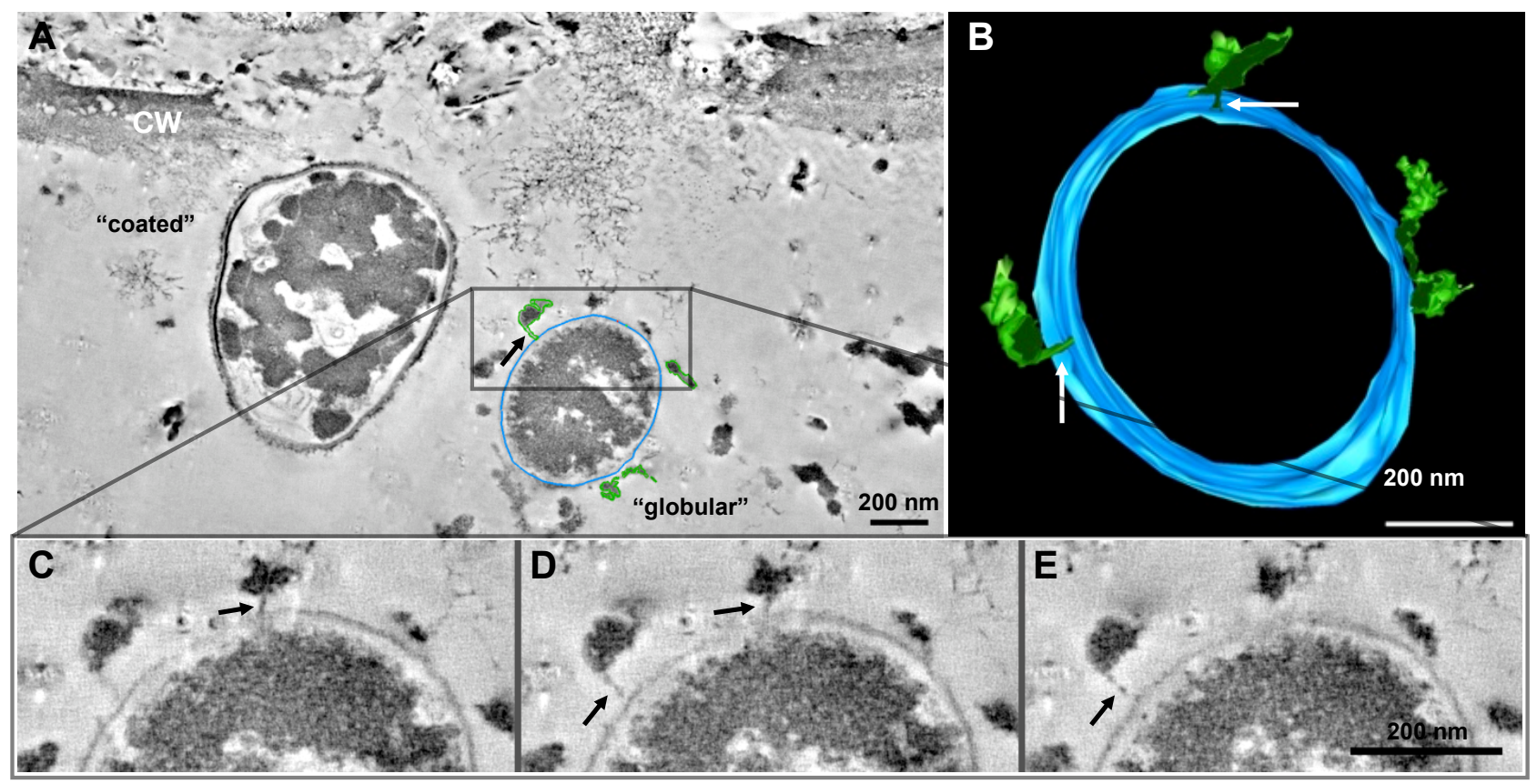

FIG. 1. Tomogram slices (A, C-E) and segmentation (B) of bacterial cells (blue) and tethered cellulosomes (green). $\mathbf{C}-\mathbf{E}$ are serial slices every $\sim 8 \mathrm{~nm}$ through the $\mathrm{z}$-axis of tethered cellulosomes. Tethers (arrows) are seen at one end of most polycellulosmes found near the bacterial cell surface and are $\sim 5 \mathrm{~nm}$ in diameter and up to $50 \mathrm{~nm}$ long. A also shows the different bacterial cell surface morphologies in nearby cells ("coated," left cell, and "globular," right cell).

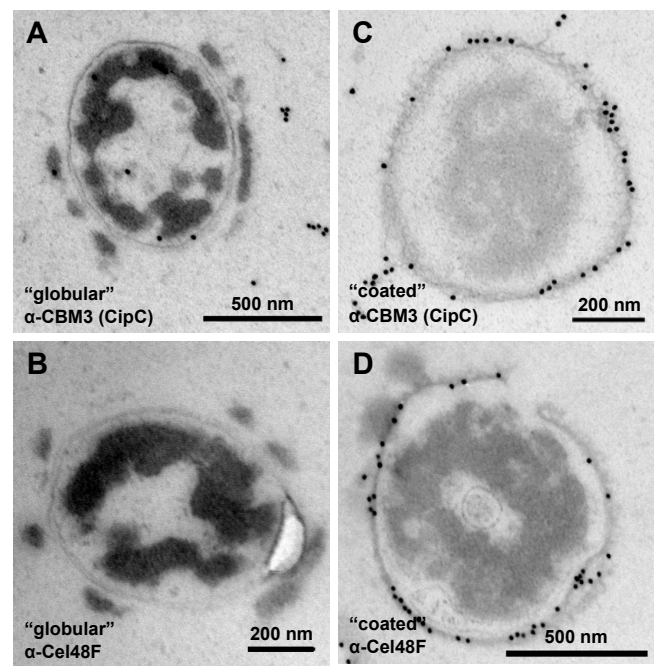

FIG. 3. Tomogram slices with models (A-E). A is a model of a degrading plant cell wall and attacking cellulosome globules. Serial tomogram slices of this area (B-E) with spacing of $\sim 8$ $\mathrm{nm}$ show free cellulomes burrowing into a scalloped cell wall surface. Cellulosomes are usually unattached to the bacterial cell surface and degrade plant cell walls distributed across the surface. Each (poly)cellulosome seems to act locally and creates an irregular digestion surface.

FIG. 2. TEM micrographs of immunolabeled sections. A and B, labeled with $\alpha$-CBM3 (CipC) and $\alpha$-Cel48F, respectively, are examples of the "globular" morphology. The "globular" morphology exhibits cellulosomal proteins in large ( $>50 \mathrm{~nm}$ dia.), irregularly-shaped globules often tethered to or near the cell surface. These globules are only occasionally labeled with $\alpha$-CBM3 (CipC) and rarely labeled with $\alpha$ Cel48F. C and D, labeled with $\alpha-C B M 3$ (CipC) and $\alpha-C e l 48 F$, respectively, are examples of the "coated" morphology. The "coated" morphology exhibits a thin layer of cellulosomal proteins around the entire cell and readily labels with antibodies to cellulosome components.

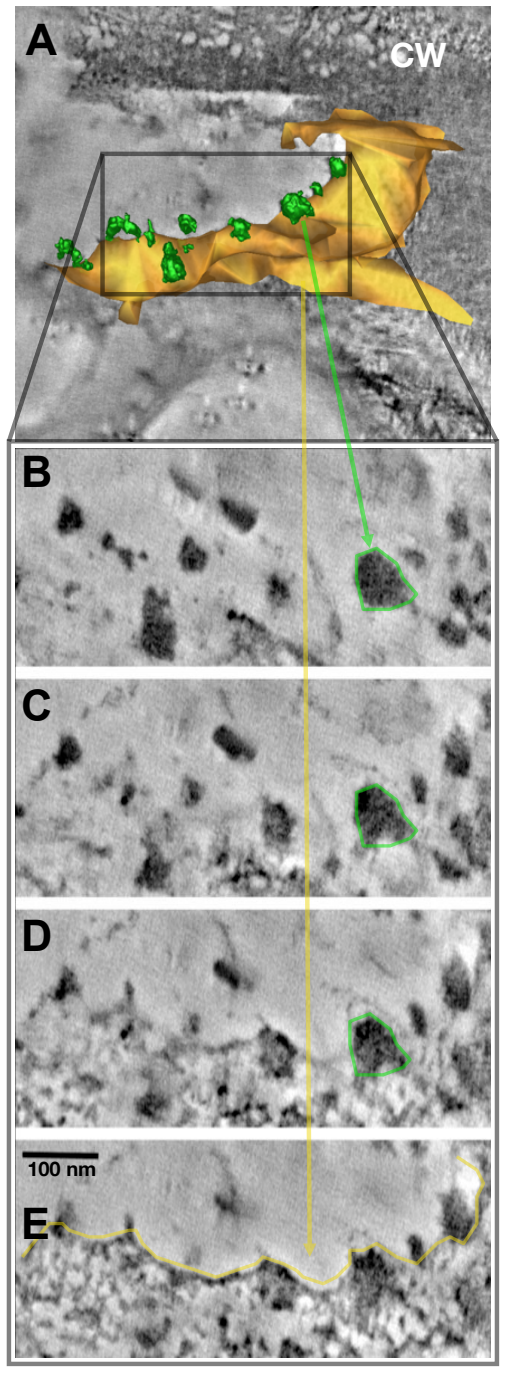

